\title{
Analysis on Chinese Compulsory Education Classroom Structure from the Perspective of ESD Strategy
}

\author{
Sihan Hua ${ }^{1}$ \\ ${ }^{1}$ Central University of Finance and Economics, Beijing 100081, China \\ Email:huasihan615@163.com

\begin{abstract}
As influences of a global scale touch aspect of everyday life, the UN come up with the Project on Education for Sustainable Development, which plays an instructive role in the structural adjustment of Chinese compulsory education classroom. In this article, both the validity and unsuited part of the present Chinese compulsory classroom structure will be discussed in details in terms of educational idea, course content, and methods. It reveals the significance of Chinese compulsory education classroom structure keeping pace with the ESD Strategy under the principle of "seek common ground and reserve differences".
\end{abstract}

Keywords: ESD Strategy, Chinses compulsory education, education concept, teaching methods

\section{INTRODUCTION}

Globalization originated from economic globalization, which has deeply affected people's life. With the further economic development, its influence gradually involves cultural globalization. The Project on Education for Sustainable Development, known as the ESD Strategy, emerged at a historic moment. Education is one of the tools used to adopt awareness about the world, to cultivate global citizen for the general goods. The UN requires participatory teaching and learning methods that motivate and empower learners to change their behaviors for sustainable development. The ESD Strategy consequently promotes competencies like critical thinking, imagining future scenarios and making decisions in a collaborative way. To practice the ESD principles, the structure of Chinese compulsory education kept changing with time.

The methods of document investigation and descriptive research method are adopted in this study. A review of the research work was presented according to lots of related references from the UN, OECD, the ESD and Chinese Ministry of Education. Based on survey and study of large amount of literatures, both the validity and drawbacks of Chinese compulsory education are discussed, in this way, the impact of ESD Strategy on the current structure of Chinese compulsory education is revealed.

By analyzing the relationship between the ESD Strategy and the structure of Chinese compulsory education classroom, this research provided readers with a deeper understanding of ESD principle, and the current educational structure.

Based on the analysis, the future trend of ESD is predicted and the improvement measures are put forward to promote the better practice of ESD principle. It is hoped that this research can raise the public awareness towards the sustainability of education.

\subsection{The ESD Strategy}

The principle of the Project on Education for Sustainable Development, known as the ESD Strategy, given by the $\mathrm{UN}$ are as follows:

The main aim of ESD Strategy is to encourage countries to integrate ESD into all forms of their education systems and covers all levels from primary to tertiary, including vocational and adult learning. The objectives of this Strategy, which will contribute to the achievement of this aim, are to:

(a) Ensure the ESD principle is supported by policy, regulatory and operational frameworks;

(b) Through formal, non-formal and informal learning, the ESD principle should be promoted ;

(c) Educators should be equipped with the competence to put forward sustainable development in their teaching;

(d) Adequate tools and materials for ESD are set to be accessible; 
(e) Promote research on and development of ESD;

(f) Strengthen cooperation on ESD at all levels within the UNECE region.

\subsection{Structure of Chinese Compulsory Education Class}

\subsubsection{Educational Concept}

Cultural values, as the concentrated embodiment of national character, determine the value orientation of education and the status of education in society. The concept of education partly lies in historical traditions. China's education emphasizes the relationship between individual and society instead of the individual itself. Confucianism values the importance of orderly society, harmony, social ethics, official accountability and consensus, which agrees with the UN's goal of cultivating global citizen to promote sustainability.

Marxism takes an undoubted guiding position in Chinese compulsory education as the State Nature requires. As Marxism agrees with the ESD principle on the view of connection and contradiction, Chinese educational value tends to be conformed with UN's idea of critical thinking, imagining future scenarios, and making decisions in a collaborative way. Guided by $\mathrm{Xi}$ Jinping's socialist ideology with Chinese characteristics for a new era, China comprehensively implement the party's educational policy, by adhering to the direction of socialist education, taking the moral education as the foundation, and improving the aesthetic and humanistic quality. It requires Chinese to carry forward the spirit of aesthetic education, to cultivates socialist builders and successors with all-round development of morality, intelligence, physique, beauty, and labor. The compilation of teaching materials tends to adhere to the guiding position of Marxism, take root in China, integrate Chinese and foreign cultures, embody the basic values of the country and the nation, be elegant in style, highlight the spirit of Chinese aesthetic education, and fully reflect the ideological, national, innovative, and practical nature. However, though China's social standard education view takes the social interest as the core, which can ensure the social harmony and world peace, it lacks individual freedom. The need for individual freedoms and human rights are being emphasized nowadays by the UN,. From the ESD's point of view, the human's status of the subject, essence of freedom and role of creation determine the human-oriented approach. That means, though the human-oriented education is pointed out by both of China and the UN, the emphasis are still not the same. The choice of primary value are still different due to the different interpretation on "human".Marxism takes an undoubted guiding position, it leaves less space for other contributing educational ideas like structural functionalism, which leads to a centralized leadership system in education. Though it serves for the purpose of social harmony, the openness and tolerance for diversity as well as human right is less concerned.

\subsubsection{Course content}

\subsubsection{Science}

Global needs of students not only include good theoretical knowledge, but also practical ability and innovative ability. In this case, the research learning conducting aims at developing student's innovative spirit and practice ability. In science field, the government put forward team-based teaching modules reform ideas to improve the student's ability in practice, which agrees with the ESD principle.

Since 1978, the Ministry of Education has formulated a list of science teaching instruments in primary and secondary schools around the syllabus and teaching materials. After that, it has been revised many times in 1985, 1993, 2000 and 2006 to standardize and guide the allocation of teaching equipment in schools in the stage of compulsory education. Adhering to the consistent tenet of "one-hundred-year plan, education oriented", in 2018, the Ministry of education once again revised the 2006 edition of "Standards For The Allocation Of Science Teaching Instruments In Junior High School", and published the standards of each discipline in separate volumes. The biology discipline formed the "Junior High School Biology Teaching Equipment Configuration Standard" (JY / T 0621-2018) The improvement of infrastructure construction shows the education system lay stress upon practice, and the classroom structure is changing to practice-dominant form. The ways to develop students' core quality as mentioned above are strengthening the experimental and other practical teaching activities, and implementing the fundamental task of moral education and cultivation of people as the goal. The adoption of a lab-based teaching model that combines group-designed project can effectively promote students 'practical ability.

\subsubsection{2. $\quad \underline{\text { Art }}$}

Art and science are a unity, like two sides of coin. However, there has been the phenomenon of inadequate attention to the disciplinary creativity in art, humanity, and social science. The innovation in humanity domain is not less important than that of the natural discipline domain. If the natural science is the tool with which a nation progresses, then the humanity science is the soul. The ability acquired by the art subject, like communicating, listening, understanding abilities are at least as important as calculating, data-analyzing, and logical-thinking abilities. Academic institutions all over the world have committed to enhance the disciplinary creativity in humanity and social science, so it is with Chinese Ministry of Education. 
The Chinese Curriculum Standard has made clear the training goal and course content of students' oral communication ability. "Chinese Curriculum Standards for Compulsory Education" (2011 edition) specifically points out the training objectives of oral communication: "to have the basic ability of daily oral communication, learn to listen, express and communicate, initially learn to use oral language to conduct interpersonal and social communication in a civilized way", and set up a "oral communication" section in the objectives and contents of the learning period to clarify the teaching of each stage of compulsory education learning objectives and teaching content.

Chinese teaching materials make full use of all kinds of learning activities to train students' oral expression ability. From the basic storytelling, retelling and reporting, topic discussion to speech, debate, interview, speech and other forms of communication, the teaching materials are involved, reflecting the systematic design of activities.

The primary school Chinese teaching materials are specially designed with "oral communication" column. Each volume is arranged with rich and colorful oral communication activities to improve students' expression ability and communication ability, such as performing textbook plays, carrying out reading meetings, theme speeches, holding debates, trying to make impromptu speeches, etc.

There are different topics in communication, such as monologue which focuses on the development of oral expression ability, especially in public expression ability; dialogue topic focusing on cultivating students' communication and discussion ability, which guides students to learn to listen to others' opinions and express their own ideas in the process of communication and discussion; and it also focuses on how to better complete the communication tasks in daily life. Functional communication topics can promote the development of students' listening, expressing and coping abilities from different perspectives. The teaching material reasonably arranges the gradient of the development of oral communication ability. Each activity puts forward the goal and requirement in line with the students' development level, such as discussion, guiding the students to learn to express in turn, the middle grade began to emphasize paying full attention to the opinions expressed by others during the discussion, and initially trying to summarize the group opinions. The senior students should respect different opinions and express different opinions in the discussion. With development of globalization, the demand for students' oral communication ability of the society is increasingly urgent.

\subsubsection{3. $\quad$ Cross-curriculum}

Art and science are not implacable, but can excavate to have great potentialities. "The Three-Year Action Plan For Project-Based Learning In Compulsory Education" (2020-2022) issued by Shanghai Education Commission recently aims to promote the reform of teaching and learning methods of compulsory education schools and further stimulate the vitality of schools by taking creative problem-solving ability as the guidance, focusing on the practice and research of project-based learning, and taking activity projects, subject projects and interdisciplinary projects as carriers.

"What if there are bullet screens on the blackboard in the school classroom?" "How to describe a fly vividly?" Projects mentioned above suggest the combination of based learning and innovative practice. It designs real and challenging problems in school activities, disciplines, and interdisciplinary fields, which guides students to explore continuously, solve problems creatively and make relevant project achievements.

We should strengthen the integration of aesthetic education with moral education, intellectual education, physical education and labor education, and fully tap and utilize the rich aesthetic education resources of various disciplines, such as the beauty of soul, etiquette and music, the beauty of language, the beauty of behavior, the beauty of science, the beauty of order, the beauty of health, the beauty of diligence and the beauty of art, which embody the spirits of Chinese aesthetic education and the aesthetic characteristics of the nation. We should organically integrate the aesthetic education contents of relevant disciplines, promote the deep integration of curriculum teaching, social practice, and culture construction, and vigorously carry out interdisciplinary education and teaching and extracurricular practice activities with aesthetic education as the theme. The cross-curriculum attempts to encourage students to integrate theories taught in school with reality, analyse and study actual conditions and solve practical problems, thus helping them deepen their understanding of the knowledge and strengthen the memory.

\subsubsection{Teaching methods}

The most important contribution of cultural globalization lies in providing a good platform for cultural exchanges between China and other countries, and it is one of the practices of ESD,

"ensure that adequate tools and materials for ESD are accessible." The important prerequisites and conditions for friendly exchanges between China and foreign countries also serves for the goal that "strengthen cooperation on ESD at all levels within the UNECE region." 
In line with the novel coronavirus pneumonia epidemic situation online teaching and student home learning practice, the Ministry of Education issued the "strengthening the ${ }^{6}$ three classroom 'application guidance", it is an attempt to use online technology as teaching methods in a large scale for a long period. The usage of online technology promotes the academic communication with other regions, adapting students with this high-technology society, and preparing them with the ability of the informative era.

In the meanwhile, however, as "Information on The Epidemic Prevention and Control Period" requires, all localities to coordinate the deployment, scientific and orderly implementation of online teaching, to provide students with eye hygiene requirements of learning environment and facilities. The online teaching time of grade three to grade six is controlled within 15-20 minutes, while that of middle school students is controlled at 25-30 minutes, to guide students to develop good habits of studying and eye hygiene. All courses on the national network cloud platform for primary and secondary schools are 15-20 minutes long.

In August 2020, the Ministry of education, together with the National Health Commission and the State General Administration of sport, printed and issued the assessment methods for comprehensive prevention and control of myopia in children and adolescents. Students are forbidden to bring mobile phones, tablet computers and other electronic products into the classroom, and those brought into the school should be kept in a unified way. School education is based on the principle of reasonable use of electronic products on the principle of demand. Teaching and homework arrangement do not rely on electronic products. In principle, the teaching time of using electronic products does not exceed $30 \%$ of the total teaching time. In principle, paper homework is used.

The online way of teaching and learning is much harder to promote than expected, as the technology is not the only barrier, health too.

\section{CONCLUSION}

Regarding the role of schools, globalization has become a major topic of study, especially in the field of comparative education, which applies historiographic and social scientific theories and methods to international issues of education.

From the perspective of ESD Strategy, this article analyzes the current structure of Chinese compulsory education classroom. When it comes to the educational concept, as the basis of Chinese educational idea, both Marxism and Confucianism agree with the ESD's principle of critical thinking, imagining future scenarios, and making decisions in a collaborative way. However, Chinese educational ideas lacks of concerning on the individual freedom. In terms of curriculum content, the reforming tends of science, art, and cross-curriculum practices are mainly discussed based on the Strategy of ESD. It reveals that the ability required by the global society is gradually put into the training process. As to educational methods, this article focusses on the online teaching-learning way. The new form of education meets the principle of"ensure that adequate tools and materials for ESD are accessible." However, as

the technology is not the only barrier when concerning about the adoption of online learning, health too, the online teaching-learning way would probably not fully take the place of traditional classroom that soon.

To better promote ESD principle, it is important for China to keep pace with the time. China should seek common ground and reserve differences on the educational concept. The improvement of education structure of a country is indeed a special development process, which is different from any other countries. It is not only a process of consciously adapting to the world, but also a process of nationalization with active creation and pioneering spirit. It is the basic requirement for the healthy development of a country's educational structure to go its own way and develop its own characteristics.

It is also important to standard the online courses, promote network governance. The progress of technology also plays an important role in stimulating the educational sustainable development. The enhancing infrastructure contributes to education prosperity.

\section{ACKNOWLEDGMENT}

First and foremost, I would like to show my deepest gratitude to my teachers, tutors, and professor Gearon from Oxford University, who have provided me with valuable guidance in every stage of the writing in this thesis. Further, I would like to thank all my friends for their fully support. Without their encouragement and kindness, I could not have completed my thesis.

\section{REFERENCES}

[1] R. Li. The Value and World Impact of Chinese Traditional Culture in the Context of Cultural Globalization[A]. Institute of Management Science and Industrial Engineering.Proceedings of 2019 3rd International Conference on Art Design,Language, and Humanities(ADLH 2019)[C].Institute of Management Science and Industrial Engineering: Computer Science and Electronic Technology International Society,2019:6.

[2] W. Gao. Sociological analysis of curriculum structure reform of compulsory education in China [J]. Journal of Tianjin Normal University (Basic Education Edition), 2014,15 (02): 11-16 
[3] G. Jin. Internationalization of basic education creates the heart of children [J]. Art of education, 2018 (06): 13-14

[4] Y. Ran. Cultural values and China's education reform [J]. Journal of Inner Mongolia Normal University (EDUCATION SCIENCE EDITION), 2010,23 (04): 1-4

[5] J.Wei, Zhongjin Lu. Organic unity of cosmopolitanism and Nationality -- an important principle of network ideological and political education management [J]. Journal of Guangxi Normal University, 2005 (02): 44-47

[6] Ministry of education of the people's Republic of China. Reply to the proposal No. 4354 (Education No. 400) of the third session of the 13th National Committee of the CPPCC [EB / OL]. http://www.moe.gov.cn/jyb_xxgk/xxgk_jyta/jyta_ jiaocaiju/202009/t20200910_486904.html

[7] Ministry of education of the people's Republic of China. Reply to the no.9882 recommendation of the third session of the 13th National People's Congress [EB / OL] http://www.moe.gov.cn/jyb_xxgk/xxgk_ jyta/jyta_twys/202010/t20201010_493745.html

[8] Ministry of education of the people's Republic of China. Reply to the recommendation no.5536 of the third session of the 13th National People's Congress [EB / OL] http://www.moe.gov.cn/jyb_xxgk/xxgk jyta/jyta jiaocaiju/202009/t20200910 486879. $\overline{\text { html }}$ 